\title{
Compliance to iron and folic acid supplementation in pregnancy, Northwest Ethiopia
}

\author{
Tesfaye Molla Birhanu', Mequanent Kassa Birarra ${ }^{1}$ and Fantahun Ayenew Mekonnen²*
}

\begin{abstract}
Objective: Strict compliance to iron and folic acid supplementation is vital for prevention of anemia in pregnancy. However, data are scarce in Ethiopia. So, we conducted this study to assess the level of compliance to iron and folic acid supplementation during pregnancy and its associated factors.

Results: Of 418 women, over half, 231 (55.3\%), adhered to the recommended iron and folic acid supplementation. Women who started antenatal care (ANC) follow up early [AOR; 95\% Cl 2.43 (1.12-5.26)], had more frequent number of ANC visit [AOR; 95\% Cl 2.73 (1.32-5.61)], took small number of tablets per visit [AOR; 95\% Cl 3.0 (1.21-7.43)], had history of anemia [AOR; 95\% Cl 1.9 (1.17-3.12)], and were from urban areas [AOR; $95 \% \mathrm{Cl} 2.2(1.29-3.77)$ ], were more likely to conform to recommended iron and folic acid supplementation. Therefore, there need to be prescription of the lowest possible number of tablets per visit. Furthermore, education targeting on increasing maternal health service utilization need to be in place. There need to also be further research aimed at determining the number of tablets to be prescribed per visit specific to individuals' background characteristics.
\end{abstract}

Keywords: Compliance/adherence, Iron and folic acid supplementation, Antenatal care, Ethiopia

\section{Introduction}

Anemia, a low blood hemoglobin concentration, is an important public health problem affecting all countries with varied impact across population segments. Pregnant women are usually among the most affected groups globally $[1,2]$. According to WHO (World Health Organization) report, $38.2 \%$ of global and $46.3 \%$ of African region pregnant women are affected by anemia [3]. In Ethiopia, the prevalence is $23 \%$ [4], which seems lower than the aforementioned global and regional prevalences. However, reports show Ethiopia is among countries in the world where the highest maternal and child mortalities are documented, which may likely be due to poor maternal services utilization like micronutrient supplementation [5].

\footnotetext{
*Correspondence: fantahunaye@gmail.com

${ }^{2}$ Department of Epidemiology and Biostatistics, Institute of Public Health, College of Medicine and Health Sciences, University of Gondar, Gondar, Ethiopia

Full list of author information is available at the end of the article
}

Maternal anemia is associated with mortality and morbidity of the mother and the baby, including risk of miscarriages, stillbirths, prematurity and low birth weight. It impairs children's development and learning too, further impacting economic productivity and development [6].

A number of causes are reported to influence the occurrence of anemia during pregnancy. Nevertheless, iron deficiency is the leading cause, constituting $41.8 \%$ of the global burden [3]. Consequently, WHO recommended $60 \mathrm{mg}$ iron plus $400 \mu \mathrm{g}$ folic acid supplementation during pregnancy in areas of iron deficiency anemia (IDA), prevalence of above 40\% [7]. However, literature indicate that the proportion of women taking iron and folic acid (IFA) supplementation is much lower, specially, in low and middle income countries, continuing to hinder the prevention of anemia. There are several factors believed to be responsible for not conforming to the recommended iron and folic acid supplementation during pregnancy which would be broadly grouped as: socioeconomic, ANC utilization and previous illness etc. [8-12]. In Ethiopia the compliance to iron and folic acid

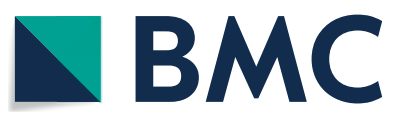

(c) The Author(s) 2018. This article is distributed under the terms of the Creative Commons Attribution 4.0 International License (http://creativecommons.org/licenses/by/4.0/), which permits unrestricted use, distribution, and reproduction in any medium, provided you give appropriate credit to the original author(s) and the source, provide a link to the Creative Commons license, and indicate if changes were made. The Creative Commons Public Domain Dedication waiver (http://creativecommons.org/ publicdomain/zero/1.0/) applies to the data made available in this article, unless otherwise stated. 
Table 1 Socio demographic characteristics ANC attendants at the University of Gondar hospital, 2017

\begin{tabular}{|c|c|c|}
\hline Variables & Frequency & Percent \\
\hline \multicolumn{3}{|l|}{ Age (years) } \\
\hline$<28$ & 204 & 48.8 \\
\hline$\geq 28$ & 214 & 51.2 \\
\hline \multicolumn{3}{|l|}{ Marital status } \\
\hline Married & 398 & 95.2 \\
\hline Single & 20 & 4.8 \\
\hline \multicolumn{3}{|l|}{ Residence } \\
\hline Urban & 308 & 73.7 \\
\hline Rural & 110 & 26.3 \\
\hline \multicolumn{3}{|l|}{ Religion } \\
\hline Orthodox Christian & 302 & 72.3 \\
\hline Muslim & 87 & 20.8 \\
\hline Protestant & 29 & 6.9 \\
\hline \multicolumn{3}{|l|}{ Occupation } \\
\hline Housewife & 192 & 45.9 \\
\hline Government employee & 112 & 26.8 \\
\hline Merchant & 64 & 15.3 \\
\hline Daily laborer & 28 & 6.7 \\
\hline Student & 22 & 5.3 \\
\hline \multicolumn{3}{|l|}{ Education status } \\
\hline Can't read and write & 97 & 23.2 \\
\hline Primary and high school & 211 & 50.5 \\
\hline College and university & 110 & 26.3 \\
\hline \multicolumn{3}{|l|}{ Family size } \\
\hline$<4$ & 191 & 45.7 \\
\hline$\geq 4$ & 227 & 54.3 \\
\hline \multicolumn{3}{|l|}{ Monthly income } \\
\hline$<\$ 148$ & 245 & 58.6 \\
\hline$\geq \$ 148$ & 173 & 41.4 \\
\hline
\end{tabular}

supplementation is between 20.4 and $60 \%$ [8-10], which is lower than what it should normally be. Nonetheless, the factors contributing for this low level of compliance have not been well studied in the country. Even no study has been conducted in our study setting so far. Therefore, we conducted this study to find out the level of compliance to iron and folic acid supplementation during pregnancy and its associated factors in Northwest Ethiopia.

\section{Main text}

\section{Methods}

\section{Study design and setting}

We conducted an institution based cross-sectional study among women attending $\mathrm{ANC}$, and currently taking the supplementation at the University of Gondar Hospital, Ethiopia. The University of Gondar Hospital is one of oldest and largest federally established teaching hospitals.
Table 2 Compliance to IFA of ANC attendants at the University of Gondar hospital, 2017

\begin{tabular}{|c|c|c|}
\hline Variables & Frequency & Percent \\
\hline \multicolumn{3}{|l|}{ Compliance to supplement } \\
\hline Yes & 231 & 55.3 \\
\hline No & 187 & 44.7 \\
\hline \multicolumn{3}{|l|}{ Reason for compliance } \\
\hline Advice of health worker & 142 & 61.5 \\
\hline Knowing it prevents anemia & 36 & 15.5 \\
\hline Getting the supplement for free & 29 & 12.6 \\
\hline Use of reminder & 24 & 10.4 \\
\hline \multicolumn{3}{|l|}{ Reason for non-compliance } \\
\hline Fear of side effects & 109 & 58.3 \\
\hline Forget fullness & 39 & 20.9 \\
\hline Too many pills & 22 & 11.8 \\
\hline Unpleasant tests & 17 & 9.0 \\
\hline \multicolumn{3}{|l|}{ Tablets collected } \\
\hline 30 & 162 & 38.8 \\
\hline 60 & 121 & 28.9 \\
\hline 90 & 106 & 25.4 \\
\hline$>90$ & 29 & 6.9 \\
\hline \multicolumn{3}{|l|}{ ANC starting time } \\
\hline First trimester & 157 & 37.6 \\
\hline Second trimester & 219 & 52.4 \\
\hline Third trimester & 42 & 10.0 \\
\hline \multicolumn{3}{|l|}{ Current anemia status } \\
\hline Yes & 143 & 34.2 \\
\hline No & 275 & 65.8 \\
\hline
\end{tabular}

It serves more than 6 million people. The hospital has different specialty units which, included internal medicine, pediatrics, gynecology/obstetrics, surgery, dentistry, psychiatry, ophthalmology, hospital pharmacy and dermatology. The study was conducted from March 8 to April 10, 2017.

\section{Sample size and sampling procedure}

We determined the sample size using single population proportion formula. We took $60 \%$ level of compliance from a previous study [9]. We also considered a 5\% level of significance $(\alpha)$ and $5 \%$ margin of error. The sample size calculated was, therefore, 384. After adding a nonresponse rate of $10 \%$, the final sample size obtained was 418 study participants.

The sample women were selected by systematic random sampling from the population attending ANC during the study period. The total number of ANC attendants (sampling frame) for the current study was assumed to be similar to the total number of ANC attendants of the 2 months preceding this study period and it was 2500 attendants. So, we divided 418 (sample) by 2500 
(sampling frame) so that a sampling fraction of $1 / 6$ was obtained. To determine the order of the first respondent, we employed simple random sampling technique among the first six participants, and it was found to be the 5th participant. Thus, every 6 th participant starting from the first respondent was then included and interviewed until we get the required sample size.

\section{Data collection and analysis}

The data were collected by interview on variables like, number of iron and folic acid tablets taken per week, reasons for missing tablets, history of anemia status, information provision regarding iron and folic acid supplementation, pregnancy and delivery related characteristics using structured and pretested questionnaire. Compliance to iron and folic acid supplementation was defined as taking iron and folic acid tablets for at least 4 days in the most recent week, which otherwise was considered as non-compliance [7]. Data were checked for consistency and completeness, and then descriptive and analytic computations were carried out. Multivariable binary logistic regression model was fitted to the data to identify predictor variables associated with the dependent variable. Variables with $\mathrm{p}<0.05$ were considered statistically significant. SPSS version 20 was used to perform the analysis.

\section{Ethical consideration}

Letter of ethical clearance was obtained from Institution Ethics Review Board of the University of Gondar. Letter of permission was secured from the University of Gondar referral hospital and informed oral consent was obtained from the study participant after providing them with the information concerning the purpose of the study, benefits and harms of participating in the study. The study participants were also told that participation in the study was completely voluntary and the information will be kept strictly confidential.

\section{Results}

\section{Socio-demographic characteristics}

The mean age of the study participants was $28 \pm 5$ years. The majority of the respondents were married, 398 (95.2\%), and urban residents, 308 (73.7\%). Three-fourth of the study participants, 302 (72.2\%), were Orthodox Christians. More than half, 227 (54.3\%), had four or more household family member. Below half, 192 (45.9\%), of the women were house wives and half, 211 (50.5\%), of them

Table 3 Predictors of compliance to IFA among ANC attendants at the University of Gondar hospital, 2017

\begin{tabular}{|c|c|c|c|c|}
\hline \multirow[t]{2}{*}{ Variables } & \multicolumn{2}{|l|}{ Compliance } & \multirow[t]{2}{*}{ COR, $(95 \% \mathrm{Cl})$} & \multirow[t]{2}{*}{ AOR, $(95 \% \mathrm{CI})$} \\
\hline & Yes, no (\%) & No, no (\%) & & \\
\hline \multicolumn{5}{|l|}{ Residence } \\
\hline Urban & $185(80.1)$ & $123(65.8)$ & $2.1(1.35-3.26)$ & $2.2(1.29-3.77)^{*}$ \\
\hline Rural & $46(19.9)$ & $64(34.2)$ & 1 & 1 \\
\hline \multicolumn{5}{|l|}{ Marital status } \\
\hline Married & $228(98.7)$ & $170(90.9)$ & $7.6(2.19-26.35)$ & $6.3(1.66-23.89)^{*}$ \\
\hline Single & $3(1.3)$ & $17(9.1)$ & 1 & 1 \\
\hline \multicolumn{5}{|l|}{ Family size } \\
\hline$\geq 4$ & $140(60.6)$ & $87(46.5)$ & $1.8(1.20-2.61)$ & $2.0(1.16-3.57)^{*}$ \\
\hline$\leq 3$ & $91(39.4)$ & $100(53.5)$ & 1 & 1 \\
\hline \multicolumn{5}{|l|}{ First ANC visit } \\
\hline First trimester & $104(45)$ & $53(28.3)$ & $2.4(1.19-4.74)$ & $2.4(1.12-5.26)^{*}$ \\
\hline Second trimester & $108(46.8)$ & $111(59.4)$ & $1.2(0.61-2.29)$ & $1.3(0.63-2.83)$ \\
\hline Third trimester & $19(8.2)$ & $23(12.3)$ & 1 & 1 \\
\hline \multicolumn{5}{|c|}{ Current anemia status } \\
\hline Yes & $93(40.3)$ & $50(26.7)$ & $1.9(1.22-2.80)$ & $1.9(1.17-3.12)^{*}$ \\
\hline No & $138(59.7)$ & $137(73.3)$ & & 1 \\
\hline \multicolumn{5}{|l|}{ Tablet collected } \\
\hline 30 & $109(47.2)$ & $53(28.3)$ & $2.9(1.3-6.54)$ & $3.0(1.21-7.43)^{*}$ \\
\hline 60 & $59(25.5)$ & $62(33.2)$ & $1.2(0.59-3.06)$ & $1.3(0.50-3.14)$ \\
\hline 90 & $51(22.1)$ & $55(29.4)$ & $1.3(0.57-3.02)$ & $1.0(0.48-2.64)$ \\
\hline$>90$ & $12(5.2)$ & $17(9.1)$ & 1 & 1 \\
\hline
\end{tabular}

"**" Significant at $5 \%$ level of significance 
attended primary or high school education. The average monthly income of study participants was $\$ 170 \pm 97 \$$ (Table 1).

\section{Compliance to iron and folic acid supplementation}

The level of compliance to iron and folic acid supplementation was 55.3\%. Around two-third, 142 (61.5\%), of the respondents, mentioned advice of the health service providers as a reason for their compliance to the supplement followed by the knowledge they had that iron and folic acid supplementation prevents anemia, 36 (15.5\%). The main reason for not taking the supplement as per the recommended, on the other hand, was fear of side effects, $116(62.0 \%)$. Two-fifth, 162 (38.8\%), of the respondents collected 30 tablets per ANC visit, and 157 (37.6\%) initiated the ANC visit during their first trimester. Onethird, 143 (34.2\%), had anemia in the current pregnancy (Table 2).

\section{Factors associated with adherence to iron and folic acid supplementation}

A total of eleven independent variables were examined for the presence of association with the dependent variable, of which six variables which included, marital status, residence, family number, ANC starting time, facing anemia in the current pregnancy, and number of tablets collected per visit were statistically significantly associated with compliance to iron and folic acid supplementation in the final multivariable logistic regression model (Table 3).

\section{Discussion}

This study estimated a 55.3\% [95\% CI:(50.74\%, 60.26\%)] level of compliance to iron and folic acid supplementation in ANC attendant women already taking the supplements, and the factors statistically significantly influencing the compliance were marital status, residence, family size, ANC starting time, facing anemia in the current pregnancy, and the number of tablets collected per ANC visit.

The level of compliance identified by this study is consistent with the result in Addis Ababa, Ethiopia (60\%) [9], but higher than the findings from other areas of Ethiopia; Mecha (20\%) [8], Mishan (39\%) [10], and Tigray (33\%) [13]. The inconsistency could be due to differences in training level of health care professionals and standard of the health care institution in the different level of health care facilities as this study was conducted on one of the few referral hospitals in the country. This explanation is supported by a study stating high adherence is expected in well-organized setups as adequate counseling and sustainable product availability are better in such facilities [14-17]. However, our finding is significantly lower than from results of studies conducted in India (80.5\%) [11] and Bicol Philippines (85\%) [12]. This difference may be due to variations in socio-cultural and political environment between the countries $[18,19]$.

Concerning the factors associated with compliance to iron and folic acid supplementation, the variables which included, marital status, residence, family number, ANC starting time, facing anemia in the current pregnancy, and number of tablets collected per visit were statistically significantly associated. Consequently, women who were urban dwellers were more likely to adhere to their supplements than rural dwellers. This is consistent with a finding of study conducted in Tigray, Ethiopia [13]. This association seems obvious that being urban resident privileges to different enabling factors as compared to rural residents. For instance, urban residents have better access to health facilities $[4,9]$. Study participants who had husbands were, similarly, more likely to comply with their supplements compared to their single counter parts. This could be due to the fact that married women gets support from their husband in many ways, like a help in remembering to take the supplement. In addition, higher family number was also associated with better adherence [13]. Women who initiated ANC follow up early was also more likely to adhere to the medicines as compared to those who initiated lately. This result is supported by study done in Bicol Philippines [20]. In the current study, women who had anemia during their recent pregnancy were more adherent than those who did not have anemia. This result is in line with a study from Mecha district, Ethiopia [8]. This may be associated with a better emphasis that might have been payed to those who were sick by health care professionals while providing health education and counseling. It might also be due to a fear in women's of further complication. In addition, participants who collected few numbers of tablets per visit had higher adherence level. This result is supported by studies from Ethiopia and Egypt [9, 21]. This is because higher number of pills had negative psychological impact on adherence. Studies concluded that as number of tablets decreases adherence to medication increases due to decreasing pill burden [20].

Overall, more than half of the ANC attendant women took the iron and folic acid supplementation as per WHO recommendation. This is an average level of compliance as compared to compliances reported from different literature. Antenatal care visit starting time, number of tablets collected per visit and current anemia status were statistically significantly associated with compliance to the iron and folic acid supplementation in ANC attendants. Therefore, there need to be prescription of the lowest possible number of tablets per visit. Furthermore, education targeting on increasing maternal health service 
utilization need to be in place. There need also be further research aimed at determining the number of tablets to be prescribed per visit specific to individuals' background characteristics.

\section{Limitations}

The results of our study might have still be affected by reporting bias since compliance was assessed using selfreported pills intake though the interview required a week-long memory.

\section{Abbreviations \\ ANC: antenatal care; EDHS: Ethiopian Demographic and Health Survey; IDA: iron deficiency anemia; WHO: World Health Organization.}

\section{Authors' contributions}

TMB, MKB, and FAM have substantial contributions to the conception, design and execution of this work and agreed to be accountable for all aspects of the work that questions related to the integrity of any part of the work were appropriately investigated and resolved. All authors read and approved the final manuscript.

\section{Author details}

${ }^{1}$ Department of Clinical Pharmacy, School of Pharmacy, College of Medicine and Health Sciences, University of Gondar, Gondar, Ethiopia. ${ }^{2}$ Department of Epidemiology and Biostatistics, Institute of Public Health, College of Medicine and Health Sciences, University of Gondar, Gondar, Ethiopia.

\section{Acknowledgements}

Authors would like to thank the study participants and data collectors.

\section{Competing interests}

The authors declare that they have no competing interests.

\section{Availability of data and materials}

The data which the authors used to produce this manuscript are available and the authors are prepared to share the raw data on request recognizing the benefits of such transparency.

\section{Consent for publication}

Not applicable.

\section{Ethics approval and consent to participate}

Ethical clearance was obtained from Institutional Review Board (IRB) of the University of Gondar and letter of permission was obtained from the University of Gondar Hospital. Informed verbal consent was obtained from each study participant after explaining the benefits and risks of participating in the study. Participation in the study was completely voluntary.

\section{Funding}

The funding body had no any role in the design of the study, collection, analysis, and interpretation of the data, and in the writing of the manuscript.

\section{Publisher's Note}

Springer Nature remains neutral with regard to jurisdictional claims in published maps and institutional affiliations.

Received: 21 March 2018 Accepted: 11 May 2018

Published online: 30 May 2018
References

1. Stoltzfus RJ, Dreyfuss ML. Guidelines for the use of iron supplements to prevent and treat iron deficiency anemia, vol. 2. Washington DC: Ilsi Press; 1998.

2. World Health Organization. Mother-baby package: implementing safe motherhood in countries: practical guide. Geneva: World Health Organization; 1996

3. World Health Organization. The global prevalence of anaemia in 2011. Geneva: World Health Organization; 2015.

4. Central Statistical Agency. Ethiopia demographic and health survey 2016. Addis Ababa: CSA and ICF: 2017.

5. World Health Organization. World health statistics 2016: monitoring health for the SDGs sustainable development goals. Geneva: World Health Organization; 2016.

6. World Health Organization. Global nutrition targets 2025: anaemia policy brief. Geneva: World Health Organization; 2014.

7. World Health Organization. Guideline: daily iron and folic acid supplementation in pregnant women. Geneva: World Health Organization; 2012.

8. Taye B, Abeje G, Mekonen A. Factors associated with compliance of prenatal iron folate supplementation among women in Mecha district, Western Amhara: a cross-sectional study. Pan Afr Med J. 2015:20(1):43.

9. Gebreamlak B, Dadi AF, Atnafu A. High adherence to iron/folic acid supplementation during pregnancy time among antenatal and postnatal care attendant mothers in Governmental Health Centers in Akaki Kality Sub City, Addis Ababa, Ethiopia: Hierarchical Negative Binomial Poisson Regression. PLoS ONE. 2017;12(1):e0169415.

10. Arega SA, Gebretsadik LA, Hussen MA. Compliance with iron folate supplement and associated factors among antenatal care attendant mothers in Misha district, south Ethiopia: community based cross-sectional study. J Environ Public Health. 2015;2015:7.

11. Godara S, Hooda R, Nanda S, Mann S. To study compliance of antenatal women in relation to iron supplementation in routine ante-natal clinic at a tertiary health care centre. J Drug Deliv Ther. 2013;3(3):71-5.

12. Lutsey PL, Dawe D, Villate E, Valencia S, et al. Iron supplementation compliance among pregnant women in Bicol, Philippines. Public health Nutr. 2008;11(1):76-82.

13. Gebre A, Afework M, Belachew E. Assessment of factors associated with adherence to iron-folic acid supplementation among urban and rural pregnant women in North Western Zone of Tigray, Ethiopia: comparative Study. Int J Nutr Food Sci. 2015;4(2):161-8.

14. Khan KS, Wojdyla D, Say L, Gülmezoglu AM, et al. WHO analysis of causes of maternal death: a systematic review. Lancet. 2006;367(9516):1066-74.

15. Kiguli J, Ekirapa KE, Okui O, Mutebi A, et al. Increasing access to quality health care for the poor: community perceptions on quality care in Uganda. Patient Preference Adherence. 2009;3:77.

16. Nezenega ZS, Tafere TE. Patient satisfaction on tuberculosis treatment service and adherence to treatment in public health facilities of Sidama zone, South Ethiopia. BMC Health Serv Res. 2013;13(1):110.

17. Hegazy NN. Quality of care and medication adherence among patients with type (2) diabetes mellitus. Egyptian Family Med J (EFMJ). 2017;1(2):5-16.

18. Arcury TA, Gesler WM, Preisser JS, Sherman J, Spencer J, et al. The effects of geography and spatial behavior on health care utilization among the residents of a rural region. Health Serv Res. 2005;40(1):135-56.

19. Jacobs B, Bigdeli M, Annear PL, Wim VD. Addressing access barriers to health services: an analytical framework for selecting appropriate interventions in low-income Asian countries. Health Policy Plan. 2011;27(4):288-300.

20. Farrell B, Merkley VF, Ingar N. Reducing pill burden and helping with medication awareness to improve adherence. Can Pharm J Revue des Pharmaciens du Can. 2013;146(5):262-9.

21. Neupane N, Sharma S, Kaphle HP. Factors affecting compliance of iron and folic acid among pregnant women attaining Western Regional Hospital, Pokhara, Nepal. Int J Res Curr Dev. 2015;1 (1):43-7. 